\title{
Evidence of Oxidant-induced Injury to Epithelial Cells during Inflammatory Bowel Disease
}

\author{
S.J. McKenzie, M.S. Baker, G.D. Buffinton, and W.F. Doe \\ Division of Molecular Medicine, John Curtin School of Medical Research, Australian National University, Canberra, A.C.T., \\ 2601, Australia
}

\begin{abstract}
Evidence of in vivo oxidant-induced injury in inflammatory bowel disease (IBD) is largely indirect. Colon epithelial crypt cells (CEC) from paired specimens of histologically normal and inflamed bowel from IBD patients with active disease were examined for altered protein thiol redox status as an indicator of oxidative damage. When CEC preparations from 22 IBD patients were labeled with the reducedthiol-specific probe $\left[{ }^{14} \mathrm{C}\right]$-iodoacetamide (IAM), there was decreased labeling of a number of proteins indicating oxidation of thiol groups in CEC from inflamed mucosa compared to paired normal mucosa, especially the loss of thiol labeling of a $37-\mathrm{kD}$ protein which was almost completely lost. The loss of reduced protein thiol status for the 37-kD band was paralleled by loss of epithelial cell glyceraldehyde3-phosphate dehydrogenase (GAPDH, EC 1.2.1.12) enzyme activity, an enzyme known to contain an essential reduced cysteine $\left(\mathrm{Cys}_{149}\right)$ at the active site. The identity of the $37-\mathrm{kD}$ protein as GADPH monomer was confirmed by $\mathrm{NH}_{2}$-terminal amino acid sequence analysis.

To examine whether this type of in vivo injury could be attributed to biologically relevant oxidants produced by inflammatory cells, CEC prepared from normal mucosa were exposed to $\mathrm{H}_{2} \mathrm{O}_{2}, \mathrm{OCl}^{-}$, nitric oxide (NO), and a model chloramine molecule chloramine T (ChT) in vitro. Dose-dependent loss of IAM labeling and GAPDH enzyme activity was observed. The efficacy $\left(\mathrm{IC}_{50}\right)$ against IAM labeling was $\mathrm{OCl}^{-}>>\mathrm{ChT}>\mathrm{H}_{2} \mathrm{O}_{2}>\mathrm{NO}(52 \pm 3,250 \pm 17,420 \pm 12$, $779 \pm 120 \mu \mathrm{M}$ oxidant) and $\mathrm{OCl}^{-}>>\mathrm{ChT}>\mathrm{NO}>\mathrm{H}_{2} \mathrm{O}_{2}$ $(89 \pm 17,256 \pm 11,407 \pm 105,457 \pm 75 \mu \mathrm{M}$ oxidant), respectively, for GAPDH enzyme activity.

This study provides direct evidence of in vivo oxidant injury in CEC from inflamed mucosa of IBD patients. Oxidation and inhibition of essential protein function by inflammatory cells is a potential mechanism of tissue injury that may contribute to the pathogenesis of the disease and sup-
\end{abstract}

M.S. Baker's present address is Department of Biological Sciences, Faculty of Science, University of Wollongong, Wollongong, N.S.W., 2522, Australia.

Address correspondence to G.D. Buffinton, Ph.D., M.D., Division of Molecular Medicine, John Curtin School of Medical Research, Australian National University, P.O. Box 334, Canberra, A.C.T., 2601, Australia. Phone: 61-06-249-2589; FAX: 61-06-249-0413.

Received for publication 18 December 1995 and accepted in revised form 15 April 1996.

J. Clin. Invest.

(C) The American Society for Clinical Investigation, Inc.

0021-9738/96/07/136/06 \$2.00

Volume 98, Number 1, July 1996, 136-141 ports the exploration of compounds with antioxidant activity as new therapies for IBD. (J. Clin. Invest. 1996. 98:136141.) Key words: glyceraldehydephosphate dehydrogenase (E.C.1.2.1.12) • protein oxidation • protein thiol • reactive oxygen species $\bullet$ inflammatory bowel disease

\section{Introduction}

The mucosal lesion in inflammatory bowel disease (IBD) $)^{1}$ is characterized by a dense inflammatory cell infiltrate mainly comprising neutrophils, macrophages, and lymphocytes. Although many inflammatory mediators secreted by these cells, including the cytokines IL-1, IL-6, IL-8, IL-10, TNF- $\alpha$, and leukotrienes together with luminal bacterial products such as bacterial lipopolysaccharide (LPS) and the chemotactic peptide fMLP, have been implicated in the mucosal injury observed in IBD (1), the molecules that mediate tissue damage remain poorly understood (2). Recent indirect evidence has, however, implicated reactive oxygen and nitrogen species (RONS) such as nitric oxide $(\mathrm{NO})$, superoxide $\left(\mathrm{O}_{2}^{-}\right)$, peroxynitrite $\left(\mathrm{ONOO}^{-}\right)$, hydrogen peroxide $\left(\mathrm{H}_{2} \mathrm{O}_{2}\right)$, and hypochlorite $\left(\mathrm{OCl}^{-}\right)$in the pathogenesis of the mucosal lesion (3-9).

Increased production of RONS has been observed after in vitro stimulation of whole colonic mucosa, mucosal macrophages, and peripheral blood monocytes of IBD patients (35). Furthermore, the coproduct of NO generation, citrulline, has been observed at greater than normal levels in the colonic lumen of patients suffering from active IBD (7) and of primates with chronic colitis (9). RONS scavengers and inhibitors of RONS production including superoxide dismutase (10-13), dimethylsulphoximide, and allopurinol (10), and $\mathrm{N}^{\mathrm{G}}$-nitroL-arginine (14) have shown some antiinflammatory effects in limited clinical trials and in animal models of IBD. These findings support a role for RONS in the pathogenesis of the mucosal lesion in IBD, yet direct evidence that RONS actually injure the inflamed mucosa in IBD is lacking. Among the many potential targets of RONS-induced injury, reduced thiol (sulphydryl) groups are particularly sensitive (15). The thiol-containing enzyme glyceraldehyde-3-phosphate dehydrogenase (GAPDH, E.C. 1.2.1.12) has been shown to be particularly susceptible to oxidation of reduced thiol groups both in vitro $(16,17)$ and during carageenin-induced arthritis (18).

The purpose of this study was to examine colon epithelial crypt cells (CEC) harvested directly from inflamed lesions of both Crohn's disease and ulcerative colitis patients for markers

1. Abbreviations used in this paper: $\mathrm{CD}$, Crohn's disease; $\mathrm{CEC}$, colon epithelial crypts; ChT, chloramine T; GSH, glutathione (reduced); GSSG, glutathione disulfide (oxidized); IBD, inflammatory bowel disease; IAM, $\left[{ }^{14} \mathrm{C}\right]$ iodoacetamide; $\mathrm{OCl}^{-}$, hypochlorite; RONS, reactive oxygen and nitrogen species; UC, ulcerative colitis. 
of RONS-induced injury by determining whether GAPDH thiols were oxidized in vivo. We report here evidence of the oxidation of GAPDH in CEC from inflamed, but not noninflamed, IBD mucosa, establishing direct evidence of RONSinduced mucosal injury in vivo in IBD.

\section{Methods}

Specimens. CEC from inflamed and noninflamed mucosa were prepared from paired specimens of inflamed and noninflamed mucosa obtained at colonoscopy or from surgically resected material from IBD patients (Crohn's disease [CD], $n=13$; ulcerative colitis [UC], $n=9)$. For in vitro studies, histologically normal mucosa was obtained from material resected from cancer-bearing colons $(\geq 10 \mathrm{~cm}$ away from any histologically abnormal mucosa). In every case the diagnosis of IBD was verified by standard clinical, radiological, endoscopic, and histological criteria. The inflammatory or noninflamed status of the paired mucosal samples from IBD patients was confirmed histologically using tissue taken from an area immediately adjacent to that used for this study. The patient cohort therapy regime was grouped as follows: (a) steroids with no 5-amino salicylic acid (5-ASA) base compounds (six patients); (b) 5-ASA-based compounds, no steroids (two patients); (c) both steroids and 5-ASA-based compounds (seven patients); $(d)$ no treatment (one patient); or other therapies including azathioprine, pain suppressants, and bacteriostatic compounds (two patients) and (e) unknown treatment (seven patients). Many patients in groups $(a)$ and $(b)$ were also prescribed compounds categorized as in $(d)$. Biopsy material from patients diagnosed with ischemic colitis and quiescent or healed colitis was available during the course of this study and served as disease controls. Tissue samples used for experimental purposes were taken and used in accordance with approval of the ACT Health Institutions Ethics Committee and John Curtin School of Medical Research Ethics Committee.

Isolation of colon epithelial crypts (CEC). Primary cultures of CEC were prepared as described previously by this laboratory with minor modifications (19). Briefly, fresh mucosal biopsies and resected colorectal material were transferred to HBSS without phenol red or glucose. Biopsies or mucosa scraped from resected material using sterile microscope slides were minced finely using a crossed scalpel technique, incubated $\left(60 \mathrm{~min}, 37^{\circ} \mathrm{C}, \leq 2 \mathrm{~g}\right.$ tissue $\left./ 10 \mathrm{ml}\right)$ in a solution containing Dispase I (Boehringer Mannheim Biochemicals, Indianapolis, IN) $1.2 \mathrm{U} / \mathrm{ml}$ and collagenase IV (Worthington Biochemical Corp., Freehold, NJ) $50 \mathrm{U} / \mathrm{ml}$ in RPMI medium (Cytosystems, Sydney, Australia) followed by trituration through a 21 gauge needle. The digest was washed in HBSS ( $75 \mathrm{~g}$ for $3 \mathrm{~min}$ ) then passed through a coarse stainless steel mesh (300-400 $\mu \mathrm{m}$ gauge) to remove mucus and undigested fragments of lamina propria. The resulting suspension was enriched for whole and partial CEC using at least six low speed sedimentation steps ( $60 \mathrm{~g}$ for $3 \mathrm{~min}$ ) to remove single cells. The purified CEC were then resuspended in Dulbecco's minimum essential medium (MEM; Gibco Laboratories, Grand Island, NY) supplemented by $20 \%$ NuSerum (Collaborative Research Inc., Bedford, MA), $4 \mathrm{mM}$ L-glutamine, $4 \%$ Luria broth, $20 \mathrm{mM}$ Hepes, $50 \mu / \mathrm{ml}$ gentamycin (Delta West, Australia), and $50 \mathrm{U} / \mathrm{ml}$ penicillin (CSL, Australia). Primary cultures of CEC in supplemented MEM were incubated $\left(37^{\circ} \mathrm{C}\right.$, $5 \% \mathrm{CO}_{2}$ ) for $16-20 \mathrm{~h}$ before use. Cell viability as assessed by trypan blue exclusion was always $\geq 98 \%$ in these preparations.

$\mathrm{NH}_{2}$-terminal amino acid sequencing. Primary CEC cultures from surgically resected noninflamed and inflamed mucosa of a patient with UC were washed twice in HBSS then resuspended and lysed in HBSS by three cycles of rapid freezing and thawing. Lysates were concentrated by centrifugation for $16-18 \mathrm{~h}$ over a $10-\mathrm{kD}$ size exclusion membrane (Centricon 10; Amicon Corp., Beverley, MA) and subjected to $10 \%$ SDS-PAGE followed by Western transfer to nitrocellulose filter (Problott). The transferred protein was then stained with $0.3 \%$ Ponceau $\mathrm{S}$ in $1 \%$ acetic acid. The portion of the filter corresponding to the $37-\mathrm{kD}$ band was excised from the polyvinyl difluo- ride membrane (Problott, Perkin Elmer/Applied Biosystems, Melbourne, Australia), destained in $1 \%$ acetic acid, and the $\mathrm{NH}_{2}$-terminal amino acid sequence was determined using an automated peptide sequencer (ABI 477A; Applied Biosystems, Inc., Foster City, CA).

Oxidative status of the active-site thiol groups in CEC. The redox status of protein thiol groups was determined using autoradiography of cellular proteins labeled with the thiol-specific reagent ${ }^{14} \mathrm{C}$-iodoacetamide $\left({ }^{14} \mathrm{C}\right.$-IAM; Amersham International, Little Chalfont, UK). CEC preparations were washed twice in HBSS and resuspended in HBSS to $10^{6}$ cells $/ \mathrm{ml}$. Preparations were then incubated with ${ }^{14} \mathrm{C}$-IAM $(1 \mu \mathrm{Ci} / \mathrm{ml})$ for $30 \mathrm{~min}$ at $37^{\circ} \mathrm{C}$ with constant gentle agitation. Treated cells were lysed by three cycles of rapid freezing and thawing and concentrated as above. Concentrates of cell lysate were separated by nonreducing 10\% SDS-PAGE, and gels were dried onto cellulose sheets (Slab Gel dryer 585; Bio-Rad Laboratories, Hercules, CA). Labeled proteins were detected by autoradiography after $14 \mathrm{~d}$ exposure to $\mathrm{x}$-ray film (Hyperfilm MP; Amersham International) at $-70^{\circ} \mathrm{C}$. Autoradiograph profiles were analyzed by densitometry $(620$ video densitometer; Bio-Rad Laboratories), and the area under the curve expressed as arbitrary units $/ 10^{6}$ cells.

Glyceraldehyde phosphate dehydrogenase (GAPDH) activity. CEC were washed twice and resuspended in $100 \mathrm{mM}$ Tris-HCI, $\mathrm{pH} 8$, with $0.5 \mathrm{mM}$ EDTA and lysed by three cycles of rapid freezing and thawing. GAPDH enzyme activity was determined as described previously (20) and adapted for use with CEC preparations. Sonicated cell lysates $(50 \mu \mathrm{l})$ in Tris-HCI/EDTA were added to a $1 \mathrm{ml}$ reaction containing, $10 \mathrm{mM} \mathrm{MgCl}, 0.2 \mathrm{mM} \mathrm{NADH}, 2 \mathrm{mM}$ ATP, $5 \mathrm{U} / \mathrm{ml}$ phosphoglycerate kinase in Tris-HCI/EDTA and preincubated for $\sim 10 \mathrm{~min}$. The reaction was initiated by the addition of 3-phosphoglycerate to a final concentration of $10 \mathrm{mM}$. Enzyme activity was then determined spectrophotometrically by monitoring the oxidation of NADH by the reverse reaction of GAPDH coupled with phosphoglycerate kinase.

In vitro oxidant exposure of CEC preparations. Primary cultures of normal CEC obtained from cancer-bearing colons were washed twice and resuspended to $10^{6}$ cells $/ \mathrm{ml}$ in HBSS. Various concentrations (125-2,000 $\mu \mathrm{M})$ of $\mathrm{H}_{2} \mathrm{O}_{2}$ (BDH Chemicals, Melbourne, Australia), $\mathrm{NaOCl}$ (Ajax Chemicals, Australia), chloramine-T (Merck, Darmstadt, Germany), and NO (in the form of diethylamine NONOate; Cayman Chemical Co., Ann Arbor, MI) in HBSS were added to CEC at $10^{6}$ cells $/ \mathrm{ml}$ and then incubated at $37^{\circ} \mathrm{C}$ for $30 \mathrm{~min}$ with constant gentle agitation. Cells were washed to remove any unreacted oxidant and resuspended in HBSS for protein thiol analysis with ${ }^{14} \mathrm{C}$ IAM or resuspended in Tris/EDTA for the determination of GAPDH enzyme activity. Decomposition of diethylamine NONOate occurs with a half-life of $2.1 \mathrm{~min}$ at $\mathrm{pH} 7.4$ resulting in $>95 \%$ decomposition within $10 \mathrm{~min}(21)$.

Statistical analysis. The Student's $t$ test was used to assess the statistical significance of patient and in vitro data. Statistical significance was accepted when $P<0.05$.

\section{Results}

Protein thiol oxidation in CEC. To analyze the redox status of protein thiols in CEC from IBD patients $\left[{ }^{14} \mathrm{C}\right]$-iodoacetamide $\left({ }^{14} \mathrm{C}-\mathrm{IAM}\right)$ was used to label reduced thiol groups selectively. Proteins concentrated from the CEC lysates were then separated by SDS-PAGE and labeled proteins were detected by autoradiography. When the proteins labeled by ${ }^{14} \mathrm{C}$-IAM in lysates of CEC from inflamed IBD mucosa were compared to those from paired normal colon mucosa, the most striking observation was the almost complete loss of ${ }^{14} \mathrm{C}$-IAM binding to a 37-kD protein from inflamed CEC. Decreased labeling of proteins of minor bands at $27,69,72$, and $86 \mathrm{kD}$ and very faint bands at 30, 31, 34, 46, 54, and $61 \mathrm{kD}$ were also observed in lysates of CEC from inflamed mucosa (Fig. $1 a$ ). Protein staining by Coomassie brilliant blue of the SDS polyacrylamide gel 


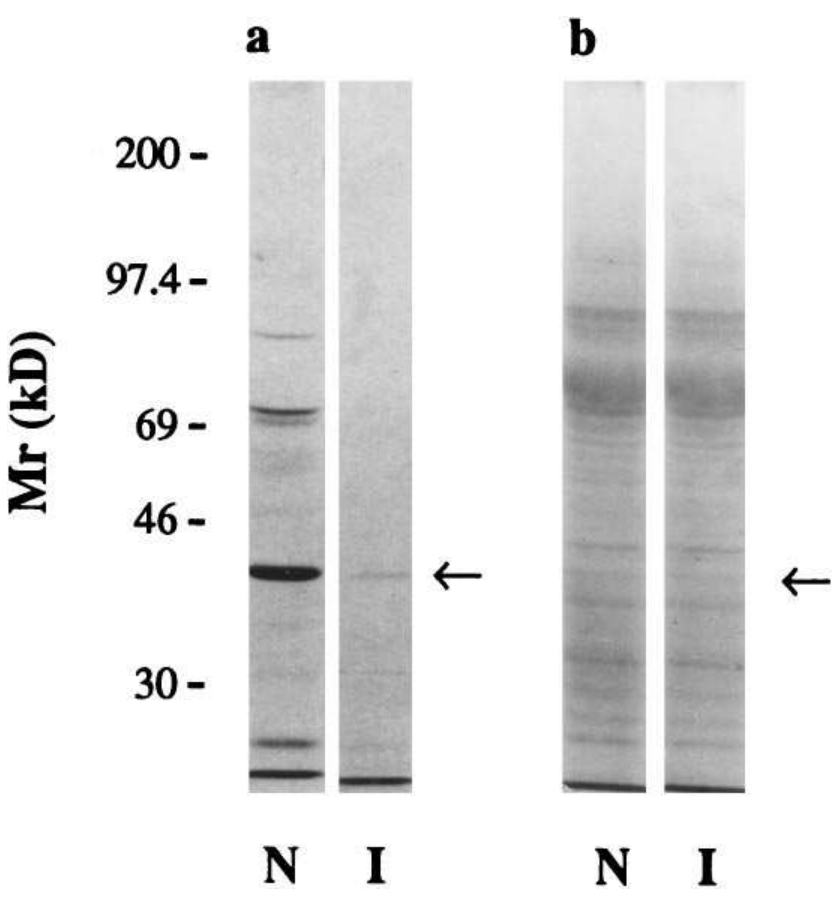

Figure 1. Identification of oxidized protein thiols in inflamed mucosa. (a) Purified CEC from the noninflamed and inflamed mucosa of an IBD patient were incubated with ${ }^{14} \mathrm{C}$-IAM, and then labeled proteins were separated by $10 \%$ SDS-PAGE and detected by autoradiography. (b) Coomassie blue staining of a SDS-PAGE gel of samples from the same patient. Arrows indicate the $37-\mathrm{kD}$ protein.

(Fig. $1 b$ ) confirmed that the proteins showing decreased ${ }^{14} \mathrm{C}$-IAM labeling, including the $37-\mathrm{kD}$ protein, were present in comparable amounts in CEC from both inflamed and noninflamed IBD mucosa indicating that the loss of ${ }^{14} \mathrm{C}$-IAM binding to the $37-\mathrm{kD}$ protein observed in CEC from inflamed IBD mucosa was due to oxidation of the thiol groups and not due to loss of the protein itself.

To identify the nature of the $37-\mathrm{kD}$ protein band obtained from SDS-PAGE-separated proteins from CEC preparations derived from both noninflamed and inflamed mucosa, the band was eluted and the protein partially $\mathrm{NH}_{2}$-terminal sequenced. The resulting $\mathrm{NH}_{2}$-terminal sequence of the $37-\mathrm{kD}$ protein that bound ${ }^{14} \mathrm{C}$-IAM in CEC from noninflamed and less avidly in inflamed mucosa, matched closely the published amino acid sequence of human GAPDH (22) (Table I), which co-migrated with the 37-kD protein on SDS-PAGE (not shown).

Oxidation of GAPDH thiols in CEC from IBD patients. Oxidation of GAPDH thiol groups was a consistent finding in all CEC preparations from inflamed IBD mucosa irrespective of whether the inflamed tissue was obtained from CD or UC patients (Fig. 2, $P<0.05$ ). No significant differences were observed in the levels of ${ }^{14} \mathrm{C}$-IAM binding to $\mathrm{CEC}$ thiol proteins between either CD and UC mucosa (Fig. 2) or between the ${ }^{14} \mathrm{C}$-IAM binding to $\mathrm{CEC}$ thiol protein bands from previously inflamed or healed IBD (quiescent colitis, $n=3$; healed ischemic colitis, $n=1$ ) mucosa compared to paired noninflamed mucosa (data not shown).

$G A P D H$ activity in CEC from IBD patients. To confirm that the decrease in ${ }^{14} \mathrm{C}$-IAM binding to the $37-\mathrm{kD}$ thiol protein was due to oxidation of the essential active-site thiol of the GAPDH monomer, GAPDH enzyme activity was measured
Table I. Comparison of $\mathrm{NH}_{2}$-terminal Amino Acid Sequences of the 37-kD Protein and Human GAPDH

\begin{tabular}{|c|c|}
\hline Sample source & $\mathrm{NH}_{2}$-terminal amino acid sequence \\
\hline Human erythrocyte & GKVKV GVNGF GR I GR LVTRA \\
\hline Noninflamed mucos & GKVKV GVNGF GR I G G LLDCD \\
\hline Inflamed mucosa & G K V K V GVNGF G R I G G LTWRA \\
\hline
\end{tabular}

The $\mathrm{NH}_{2}$-terminal amino acid sequences of the $37-\mathrm{kD}$ protein purified from CEC from both noninflamed and inflamed colonic mucosa showed almost complete homology with the published sequence of human GAPDH. The deviations from the known sequence (underlined) indicated limitations in amino acid detection due to sample size.

in CEC from paired samples of inflamed and noninflamed IBD mucosa. As shown in Fig. 3, there was a significant loss of GAPDH activity in CEC from inflamed mucosa from both $\mathrm{CD}$ and UC patients compared to CEC from paired normal mucosa $(P<0.05)$ that corresponded to the decreases seen in ${ }^{14} \mathrm{C}$-IAM binding to the $37-\mathrm{kD}$ protein (Fig. 2 ). There was no significant difference in CEC GAPDH activity between CD and UC mucosa nor between CEC preparations from previously inflamed or healed IBD (quiescent colitis, $n=3$; healed ischemic colitis, $n=1$ ) mucosa compared to paired noninflamed mucosa (data not shown).

Although the numbers of patients in each category of drug treatment were small (see Methods), there was no apparent effect on ${ }^{14} \mathrm{C}$-IAM-binding or GAPDH enzyme activity.

Oxidation and inhibition of GAPDH function by exposure to $C E C$ to oxidants in vitro. To determine the mechanism of oxidation and inactivation of GAPDH observed in CEC from inflamed IBD mucosa, CEC prepared from normal colon resection material were exposed to the biologically relevant oxidants: $\mathrm{OCl}^{-}, \mathrm{H}_{2} \mathrm{O}_{2}, \mathrm{NO}$, and chloramine- $\mathrm{T}$ (ChT), to simulate the oxidative stress that might occur during active mucosal inflammation in IBD. As demonstrated in Fig. 4, in vitro exposure to these oxidants caused a dose-dependent loss of IAMbinding that was statistically significant when compared to control binding of IAM by CEC not exposed to oxidants. The

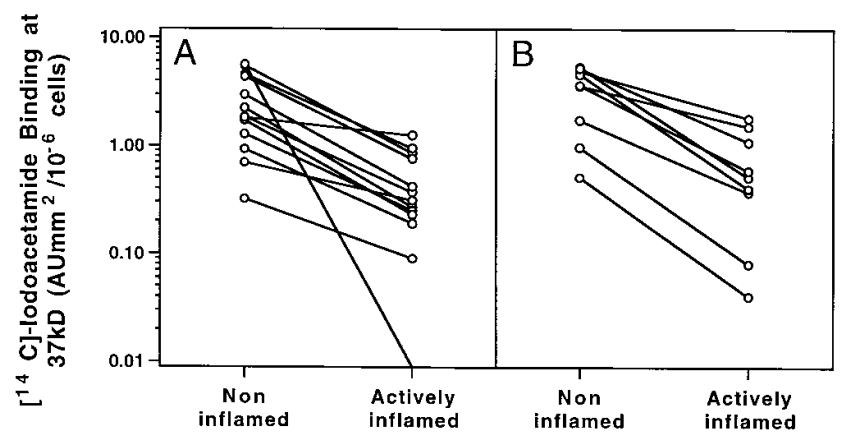

Figure 2. Oxidation of the 37-kD GAPDH monomer of CEC from IBD patients. Primary cultures of CEC from colonic mucosa of patients with $(A)$ Crohn's disease $(n=13)$ and $(B)$ ulcerative colitis $(n=9)$ were incubated with ${ }^{14} \mathrm{C}$-IAM $\left(1 \mu \mathrm{Ci} / \mathrm{ml}, 30 \mathrm{~min}, 37^{\circ} \mathrm{C}\right)$, lysed, and CEC proteins separated by SDS-PAGE. The density of the autoradiograph band corresponding to the $37-\mathrm{kD}$ protein was determined by video densitometry. Data collected from preparations of the noninflamed and inflamed colonic mucosa from the same patient are connected by lines. 


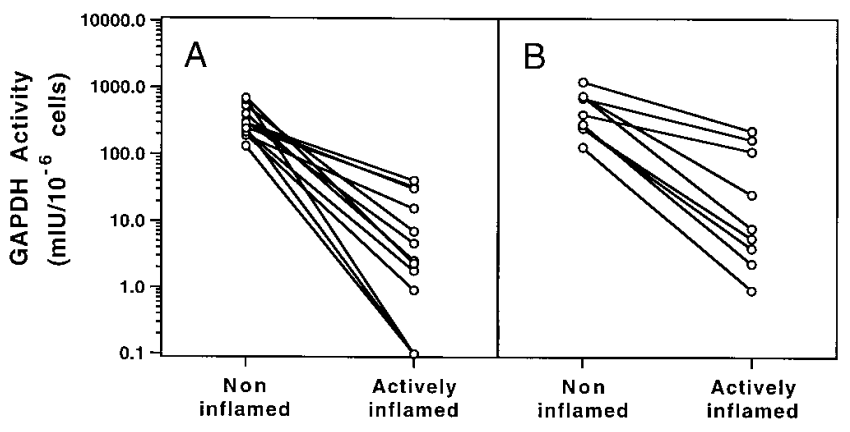

Figure 3. Inhibition of GAPDH function of CEC from IBD patients. The GAPDH enzyme activity of primary cultures of CEC from patients with $(A)$ Crohn's disease and $(B)$ ulcerative colitis was determined spectrophotometrically. Data collected from preparations of noninflamed and inflamed colonic mucosa from the same patient are connected by lines.

order of efficacy of the oxidants in decreasing IAM binding calculated from the $\mathrm{IC}_{50}$ was $\mathrm{OCl}^{-}>>\mathrm{ChT}>\mathrm{H}_{2} \mathrm{O}_{2}>\mathrm{NO}$ (Table II). Consistent with these findings, exposure to each of the oxidants markedly decreased GAPDH enzyme activity of CEC in a dose-dependent manner (Fig. 5). The order of efficacy of the oxidants in inhibiting GAPDH activity calculated from the $\mathrm{IC}_{50}$ was $\mathrm{OCl}^{-}>>\mathrm{ChT}>\mathrm{NO}>\mathrm{H}_{2} \mathrm{O}_{2}$ (Table II).

\section{Discussion}

Oxidation of GAPDH active-site thiols and subsequent inhibition of enzyme activity were consistent observations in preparations of CEC from inflamed mucosa of Crohn's disease and ulcerative colitis patients whereas there were no significant differences between GAPDH thiol redox status and enzyme activity of CEC from healed (i.e., previously inflamed) or from paired samples of unaffected mucosa.

RONS produced by activated neutrophils and macrophages (23) are the most likely cause of the oxidative inhibition of GAPDH detected in the inflamed mucosa. The capacity of RONS to initiate this observed thiol oxidation was confirmed in vitro by exposure of primary CEC cultures to $\mathrm{H}_{2} \mathrm{O}_{2}, \mathrm{OCl}^{-}$, NO, and ChT. This exposure resulted in oxidation and inhibition of GAPDH as observed in CEC from the inflamed mucosa of IBD patients. The $37-\mathrm{kD}$ monomer of GAPDH contains three thiol groups, two of which are involved in disulfide linkages between monomers to form the GAPDH tetramer, while the remaining reduced thiol group at $\mathrm{Cys}_{149}$ is an essential component of the enzyme active site (24). The $\mathrm{Cys}_{149}$ thiol must be reduced to act as a nucleophile during the NAD ${ }^{+}$catalyzed dehydrogenation of the substrate glyceraldehyde-3-phosphate. Inhibition of GAPDH activity can be

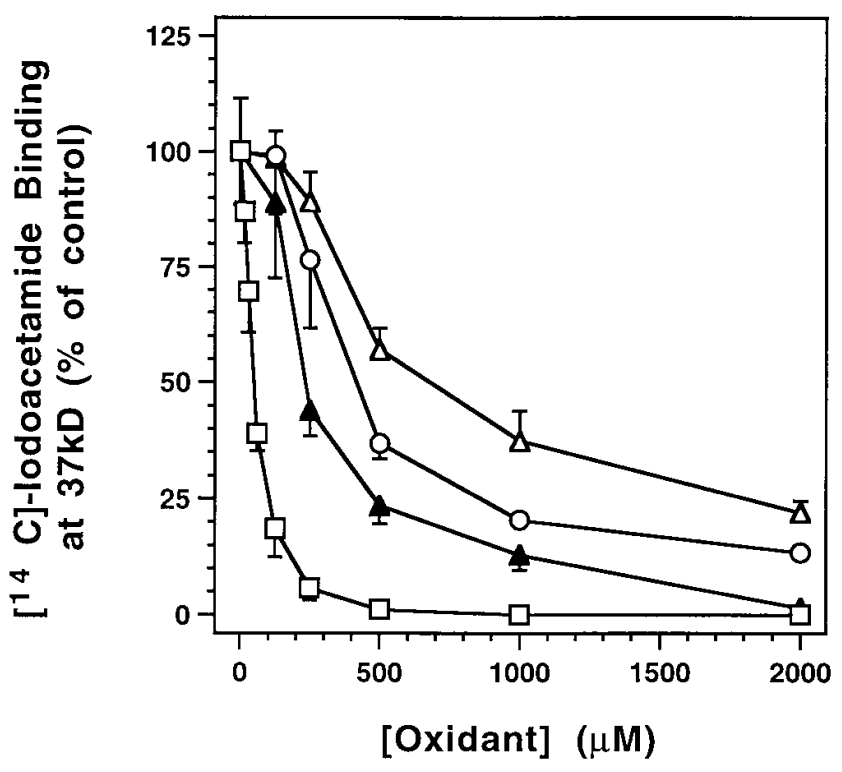

Figure 4. Oxidation of the active-site thiol group of GAPDH after oxidant stress. The ${ }^{14} \mathrm{C}-\mathrm{IAM}$ binding capacity of the $37-\mathrm{kD}$ GAPDH monomer from primary cultures of CEC $\left(10^{6}\right.$ cells $\left./ \mathrm{ml}\right)$ was determined after $30 \mathrm{~min}$ in vitro exposure to $\mathrm{OCl}^{-}(\square), \mathrm{H}_{2} \mathrm{O}_{2}(\bigcirc), \mathrm{NO}(\triangle)$, and $\operatorname{ChT}(\boldsymbol{\Lambda})$. Error bars represent mean $\pm \operatorname{SEM}(n=3)$.

mediated by direct oxidation of the $\mathrm{Cys}_{149}$ by reaction with oxidants and regenerated in the presence of reduced glutathione (GSH) $(16,24)$. Oxidant stress is known to increase the levels of glutathione disulfide (GSSG) (25), which, if not reduced or exteriorized, may participate in protein S-thiolation reactions forming mixed disulfides with reduced protein thiols (26) and possibly with the $\mathrm{Cys}_{149}$ in GAPDH. The normal homeostatic mechanism of exteriorization of GSSG is an energy-dependent process (27), and the decreased NADPH and ATP levels (28) and mitochondrial function (29) in inflamed mucosa from IBD patients are likely to compromise both the re-reduction and/or transport of excessive GSSG and to increase the opportunity for participation in intracellular S-thiolation reactions with proteins. Indeed, exposure of rat small intestine to luminal $\mathrm{H}_{2} \mathrm{O}_{2}$ causes an increase in epithelial cell GSSG content and an associated increase in protein mixed disulfide formation (30). However, S-thiolation of GAPDH in endothelial cells after exposure to $\mathrm{H}_{2} \mathrm{O}_{2}$ in vitro and subsequent enzyme inhibition was unlikely to occur via a simple reaction between formed GSSG and protein thiol groups since S-thiolation of GAPDH did not occur in the presence of appreciable concentrations of GSSG (17). The authors suggested that GSH may react directly with GAPDH via the formation of a thiyl radical intermediate, as

Table II. Order of Oxidant Inhibition of IAM Binding and GAPDH Activity

\begin{tabular}{|c|c|c|c|c|c|c|c|c|}
\hline \multicolumn{5}{|c|}{ Inhibition of $\left[{ }^{14} \mathrm{C}\right]-$ IAM binding } & \multicolumn{4}{|c|}{ Inhibition of GAPDH activity } \\
\hline Oxidant & $\mathrm{OCI}^{-}>>$ & ChT $>$ & $\mathrm{H}_{2} \mathrm{O}_{2}>$ & NO & $\mathrm{OCI}^{-}>>$ & ChT $>$ & $\mathrm{NO}>$ & $\mathrm{H}_{2} \mathrm{O}_{2}$ \\
\hline $\mathrm{IC}_{50}$ & 52 & 250 & 420 & 779 & 89 & 256 & 407 & 457 \\
\hline$\pm \mathrm{SD}(n=3)$ & 3 & 17 & 12 & 120 & 17 & 11 & 105 & 75 \\
\hline
\end{tabular}

Units, $\mu \mathrm{M}$ oxidant. 


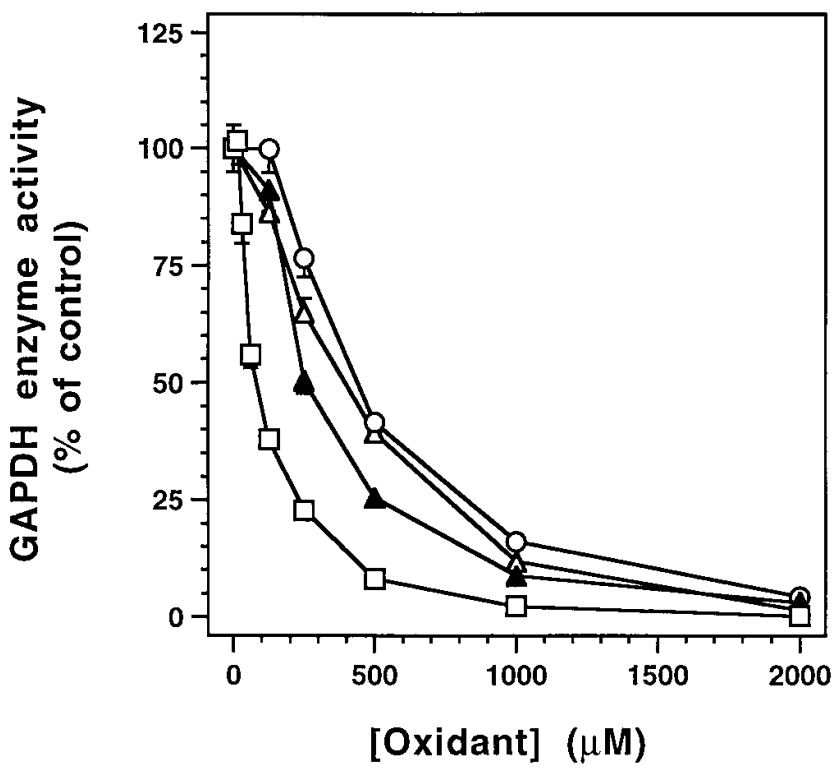

Figure 5. Inhibition of GAPDH enzyme activity after oxidant stress. The GAPDH enzyme activity of primary cultures of CEC $\left(10^{6}\right.$ cells/ $\mathrm{ml}$ ) was determined after $30 \mathrm{~min}$ in vitro exposure to $\mathrm{OCl}^{-}(\square), \mathrm{H}_{2} \mathrm{O}_{2}$ $(\bigcirc)$, NO $(\triangle)$, and $\operatorname{ChT}(\Delta)$. Error bars represent mean $\pm \operatorname{SEM}(n=3)$.

has been reported for the S-thiolation of hemoglobin within erythrocytes (31). Physiologically, these events may provide a rationale for the observed decrease in GSH in active IBD lesions compared to paired normal mucosa $(32,33)$.

The inhibition of GAPDH in vivo is likely to be more complex than the simple interaction between RONS and the active-site thiol group. Direct inhibition of GAPDH activity by $\mathrm{H}_{2} \mathrm{O}_{2}$ is followed by autoreduction of the enzyme (24). However, in CEC from inflamed IBD mucosa, the loss of IAMlabeling capacity and inhibition of GAPDH activity did not recover despite incubation for $16 \mathrm{~h}$ in complete media under nonoxidative conditions (see Methods), suggesting that the occurrence of other reactions contribute to the oxidation of the reduced thiol. Direct oxidation by NO leads to the formation of irreversible oxidation conjugates that cannot be re-reduced by cytoplasmic constituents (34-36). Initially, NO reacts with the GAPDH active-site thiol to form a reversible nitrosothiol. Upon the binding of the cofactor $\mathrm{NAD}^{+}$to its binding site adjacent to the $\mathrm{Cys}_{149}$-nitrosothiol, the nitroso moiety is able to participate in the formation of an irreversible reaction with $\mathrm{NAD}^{+}$. This irreversible reaction inhibits the ${ }^{14} \mathrm{C}$-IAM binding to GAPDH and represents a potential mechanism of GAPDH inhibition in IBD consistent with the recent report of increased NO production by the IBD mucosa (7).

The RONS-induced injury to protein thiols in CEC from IBD patients is unlikely to be limited to inhibition of GAPDH, as decreased IAM labeling of four other minor unidentified proteins with apparent molecular weights of $27,69,72$, and 86 $\mathrm{kD}$ was observed in CEC from inflamed mucosa. Exposure of human umbilical vein endothelial cells to different oxidants demonstrated that the nature of the oxidant can determine the specificity of the protein thiols that are oxidized (37). Exposure to $\mathrm{H}_{2} \mathrm{O}_{2}$ caused S-thiolation of a group of proteins of 14 , 24 , and $39 \mathrm{kD}$, with the $39-\mathrm{kD}$ protein later being identified as GAPDH (17). By contrast, treatment with diamide or $t$-butyl hydroperoxide which resulted in S-thiolation of two subsets of proteins of $14,24,34,44$, and $14,24 \mathrm{kD}$, respectively, and did not affect the $39-\mathrm{kD}$ protein $(17,37)$.

The complex and interrelated nature of RONS-induced cytotoxicity and DNA injury have led to proposals that inhibition of GAPDH could also occur as a result of depletion of the essential cofactor $\mathrm{NAD}^{+}$via RONS-induced activation of the DNA repair enzyme poly-(ADP ribose) polymerase (PARP) (38). While this would not have influenced the determination of GAPDH enzyme activity in the presence of excess cofactor as in this study, the increased PARP activity detected in IBD patients (39) may exacerbate the marked thiol-mediated inhibition of GAPDH in CEC seen in inflamed IBD mucosa. The importance of the observed inhibition of glycolysis via inhibition of GAPDH in IBD, however, remains unclear as CEC from normal colonic mucosa derive the majority of their energy requirements from $\beta$-oxidation of short-chain fatty acids (40).

The development of new strategies for therapies for IBD has been hampered by the lack of a clear understanding of the molecular basis of its pathogenesis. Intervention by targeting therapies to specific immunoregulatory mediators is often thwarted by the multiple overlapping functions of proinflammatory cytokines that are known to be involved in IBD. A more direct therapeutic strategy aimed at blocking the chemical species that cause actual tissue injury offers the prospect of more targeted therapies. In this context, the evidence presented here of RONS-induced injury to the colonic mucosa of IBD patients indicates considerable potential for new therapies based on the prevention of oxidative injury.

\section{Acknowledgments}

The authors wish to thank the staff of the operating theatres and the Departments of Pathology and Gastroenterology at Woden Valley Hospital, Canberra, A.C.T. and Repatriation General Hospital (Concord), Sydney, N.S.W. We also wish to thank the staff of the Biomolecular Resources Facility, John Curtin School of Medical Research, for help in determining peptide sequences and Dr. R. Cunningham for advice on statistical analysis.

\section{References}

1. Sartor, R.B. 1994. Cytokines in intestinal inflammation: pathophysiological and clinical considerations. Gastroenterology. 106:533-539.

2. Babbs, C.F. 1992. Oxygen radicals in ulcerative colitis. Free Radical Biol. \& Med. 13:169-181.

3. Williams, J.G., L.E. Hughes, and M.B. Hallett. 1990. Toxic oxygen metabolite production by circulating phagocytic cells in inflammatory bowel disease. Gut. 31:187-193.

4. Mahida, Y.R., K.C. Wu, and D.P. Jewell. 1989. Respiratory burst activity of intestinal macrophages in normal and inflammatory bowel disease. Gut. 30: 1362-1370.

5. Simmonds, N.J., R.E. Allen, T.R.J. Stevens, R. Niall, M. Van-Someren, D.R. Blake, and D.S. Rampton. 1992. Chemiluminescence assay of mucosal reactive oxygen metabolites in inflammatory bowel disease. Gastroenterology. 103:186-196.

6. Grisham, M.B., T.S. Gaginella, C. von Ritter, H. Tamai, R.M. Be, and D.N. Granger. 1990. Effects of neutrophil-derived oxidants on intestinal permeability, electrolyte transport, and epithelial cell viability. Inflammation. 14:531542.

7. Middleton, S.J., M. Shorthouse, and J.O. Hunter. 1993. Increased nitric oxide synthesis in ulcerative colitis. Lancet. 341:465-466.

8. Grisham, M.B., and T. Yamada. 1992. Neutrophils, nitrogen oxides and inflammatory bowel disease. Ann. N.Y. Acad. Sci. 664:103-115.

9. Ribbons, K.A., X.-J. Zhang, J.H. Thompson, S.S. Greenberg, W.M. Moore, C.M. Kornmeier, M.G. Currie, N. Lerche, J. Blanchard, D.A. Clark, and M.J.S. Miller. 1995. Potential role of nitric oxide in a model of chronic colitis in Rhesus Macaques. Gastroenterology. 108:705-711.

10. Keshavarzian, A., G. Morgan, S. Sedghi, J.M. Gordon, and M. Doria. 
1990. Role of reactive oxygen metabolites in experimental colitis. Gut. 31:786790.

11. von Ritter, C., M.B. Grisham, M. Hollwarth, W. Inauen, and D.N. Granger. 1989. Neutrophil-derived oxidants mediate formyl-methionyl-leucylphenylalanine-induced increases in mucosal permeability in rats. Gastroenterology. 97:778-780.

12. Niwa, Y., K. Somiya, A.M. Michelson, and K. Puget. 1985. Effect of liposomal-encapsulated superoxide dismutase on active oxygen-related human disorders. A preliminary study. Free Radical Res. Commun. 1:137-153.

13. Emerit, J., S. Pelletier, J. Likforman, C. Pasquier, and A. Thuillier. 1991. Phase II trial of copper zinc superoxide dismutase (CuZn SOD) in treatment of Crohn's disease. Free Radic. Res. Commun. 12-13:563-569.

14. Miller, M.J.S., H. Sadowska-Krowicka, S. Chotinaruemol, J.L. Kakkis, and D.A. Clark. 1993. Amelioration of chronic ileitis by nitric oxide synthase inhibition. J. Pharmacol. Exp. Ther. 264:11-16.

15. Armstrong, D.A., and J.D. Buchanan. 1978. Reactions of $\mathrm{O}_{2}^{-}, \mathrm{H}_{2} \mathrm{O}_{2}$ and other oxidants with sulfhydryl enzymes. Photochem. Photobiol. 28:743-755.

16. Brodie, A.E., and D.J. Reed. 1990. Cellular recovery of glyceraldehyde3-phosphate dehydrogenase activity and thiol status after exposure to hydroperoxides. Arch. Biochem. Biophys. 276:212-218.

17. Schuppe Koistinen, I., P. Moldeus, T. Bergman, and I.A. Cotgreave. 1994. S-thiolation of human endothelial cell glyceraldehyde-3-phosphate dehydrogenase after hydrogen peroxide treatment. Eur. J. Biochem. 221:1033-1037.

18. Baker, M.S., S. Bolis, and D.A. Lowther. 1991. Oxidation of articular cartilage glyceraldehyde-3-phosphate dehydrogenase (G3PDH) occurs in vivo during carrageenin-induced arthritis. Agents Actions. 32:299-304.

19. Gibson, P.R., E. van de Pol, L.E. Maxwell, A. Gabriel, and W.F. Doe. 1989. Isolation of colonic crypts that maintain structural and metabolic viability in vitro. Gastroenterology. 96:283-291.

20. Beutler, E. 1984. Glyceraldehyde phosphate dehydrogenase (GAPDH). In Red Cell Metabolism: A Manual of Biochemical Methods. 3rd. edition. Grune and Stratton, Inc., Orlando, FL. 55-56.

21. Maragos, C.M., D. Morley, D.A. Wink, T.M. Dunams, J.E. Saavedra, A. Hoffman, A.A. Bove, L. Isaac, J.A. Hrabie, and L.K. Keefer. 1991. Complexes of NO with nucleophiles as agents for the controlled biological release of nitric oxide. Vasorelaxant effects. J. Med. Chem. 34:3242-3247.

22. Nowak, K., M. Wolny, and T. Banas. 1981. The complete amino acid sequence of human muscle glyceraldehyde 3-phosphate dehydrogenase. FEBS Lett. 134:143-146.

23. Grisham, M.B. 1994. Oxidants and free radicals in inflammatory bowel disease. Lancet. 344:859-861.

24. Brodie, A.E., and D.J. Reed. 1987. Reversible oxidation of glyceraldehyde-3-phosphate dehydrogenase thiols in human lung carcinoma cells by hydrogen peroxide. Biochem. Biophys. Res. Commun. 148:120-125.

25. Sies, H., and T.P. Akerboom. 1984. Glutathione disulfide (GSSG) efflux from cells and tissues. Methods Enzymol. 105:445-451.

26. Griffiths, J.C., H. Sies, P.J. Meier, and T.P. Akerboom. 1987. Inhibition of taurocholate efflux from rat hepatic canalicular membrane vesicles by glutathione disulfide. FEBS Lett. 213:34-38.

27. Ishikawa, T., M. Zimmer, and H. Sies. 1986. Energy linked cardiac transport system for glutathione disulfide. FEBS Lett. 200:128-132.

28. Kameyama, J.-I., H. Narui, M. Inui, and T. Sato. 1984. Energy level in large intestine mucosa in patients with ulcerative colitis. Tohoku J. Exp. Med. 143:253-254.

29. O'Morain, C., P. Smethurst, J. Levi, and T.J. Peters. 1985. Subcellular fractionation of rectal biopsy homogenates from patients with inflammatory bowel disease. Scand. J. Gastroenterol. 20:209-214.

30. Benard, O., and K.A. Balasubramanian. 1993. Effect of oxidant exposure on thiol status in the intestinal mucosa. Biochem. Pharmacol. 45:20112015.

31. Maples, K.R., C.H. Kennedy, S.J. Jordan, and R.P. Mason. 1990. In vivo thiyl free radical formation from hemoglobin following administration of hydroperoxides. Arch. Biochem. Biophys. 277:402-409.

32. Buffinton, G.D., and W.F. Doe. 1995. Depleted mucosal antioxidant defences in inflammatory bowel disease. Free Radical Biol. \& Med. 19:911-918.

33. Lauterburg, B.H., M. Bilzer, E. Rowedder, and W. Inauen. 1988. Decreased glutathione in inflamed colonic mucosa in man. Possible role of hypochlorous acid and prevention by 5-aminosalicylic acid. In Inflammatory Bowel Disease: Current Status and Future Approach. R.P. MacDermott, editor. Elsevier Science Publishers B.V., Amsterdam. 273-276.

34. Dimmeler, S., F. Lottspeich, and B. Brüne. 1992. Nitric oxide causes ADP-ribosylation and inhibition of glyceraldehyde-3-phosphate dehydrogenase. J. Biol. Chem. 267:16771-16774.

35. Kots, A.Y., A.V. Skurat, E.A. Sergienko, T.V. Bulargina, and E.S. Severin. 1992. Nitroprusside stimulates the cysteine-specific mono (ADP-ribosylation) of glyceraldehyde-3-phosphate dehydrogenase from human erythrocytes. FEBS Lett. 300:9-12.

36. Zhang, J., and S.H. Snyder. 1992. Nitric oxide stimulates auto-oxidation of glyceraldehyde-3-phosphate dehydrogenase. Proc. Natl. Acad. Sci. USA. 89: 9382-9385.

37. Schuppe, I., P. Moldéus, and I.A. Cotgreave. 1992. Protein-specific S-thiolation in human endothelial cells during oxidative stress. Biochem. Pharmacol. 44:1757-1764.

38. Schraufstätter, I.U., D.B. Hinshaw, P.A. Hyslop, R.G. Spragg, and C.G. Cochrane. 1986. Oxidant injury of cells: DNA strand breaks activate polyadenosine diphosphate-ribose polymerase and lead to depletion of nicotinamide adenine dinucleotide. J. Clin. Invest. 77:1312-1320.

39. Markowitz, M.M., P. Rozen, R.W. Pero, M. Tobi, and D.G. Miller. 1988. Hydrogen peroxide induced adenosine diphosphate ribosyl transferase (ADPRT) response in patients with inflammatory bowel disease. Gut. 29:16801686.

40. Roediger, W.E.W. 1982. Utilization of nutrients by isolated epithelial cells of the rat colon. Gastroenterology. 83:424-429. 